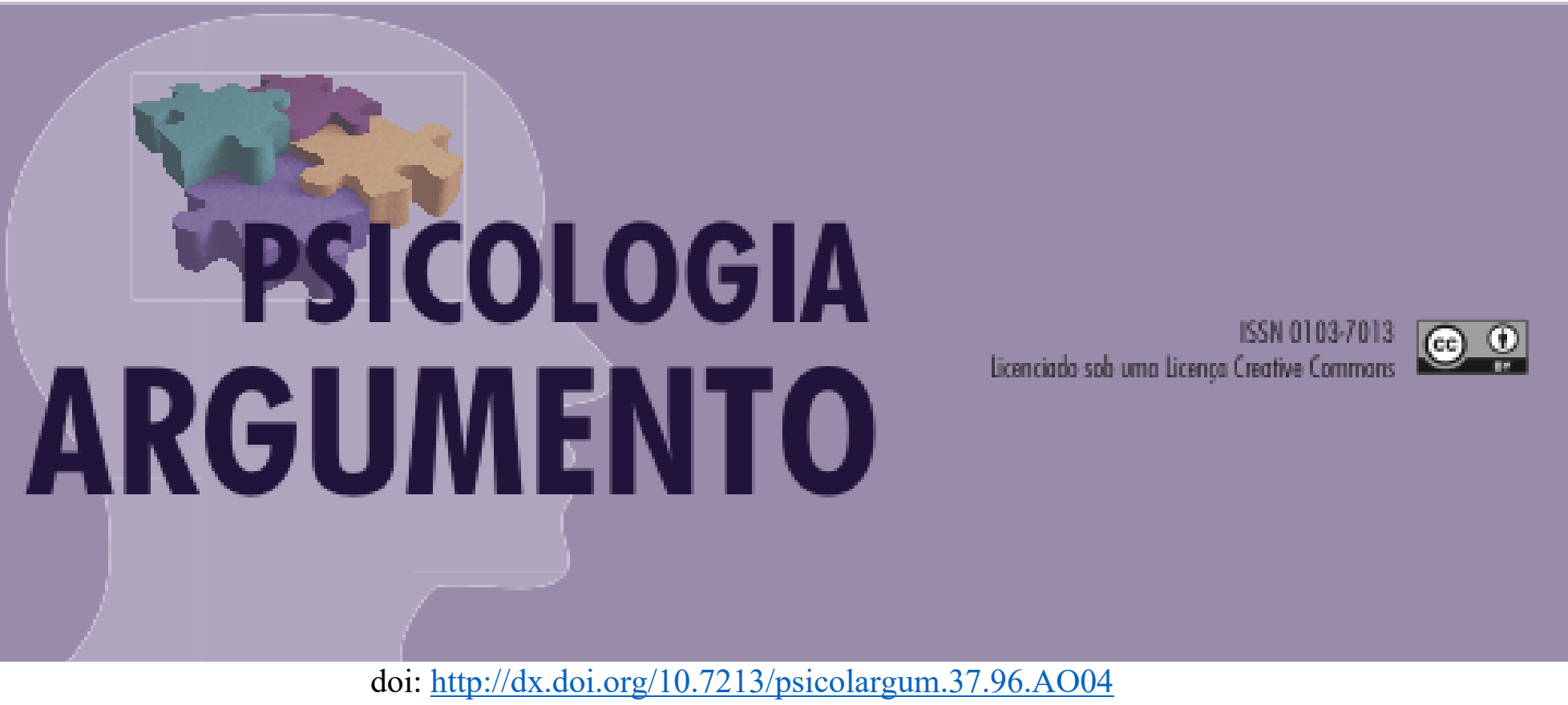

\title{
A escolha das(os) acadêmicas(os) de pedagogia a constituição de uma identidade profissional.
}

The choice of the pedagogy academics the constitution of a professional identity
La elección de los académicos de pedagogía la constitución de una identidad profesional

\author{
Carolina Zanella de Queiroz \\ https://orcid.org/0000-0003-4617-4025
}

Psicopedagoga atua em clina particular, Curitiba, Paraná, Brasil

Denise de Camargo

https://orcid.org/0000-0001-9092-9988

Docente da Universidade Federal do Paraná e do Mestrado em Psicologia da Universidade Tuiuti do Paraná, Curitiba, Paraná, Brasil

\author{
Maria Sara de Lima Dias \\ http://orcid.org/0000-0001-7296-6400
}

Docente da Universidade Tecnológica Federal do Paraná, Curitiba, Paraná, Brasil

\begin{abstract}
Resumo:
Esta pesquisa volta-se para a escolha profissional dos acadêmicos de Pedagogia com o objetivo de conhecer como se dá essa escolha e quais as expectativas desses estudantes quanto à inserção no mercado. Pretende-se problematizar sobre a constituição de uma identidade profissional comprometida com as ações pedagógicas. Trata-se de uma pesquisa qualitativa exploratória, cujos dados foram coletados por meio de quinze entrevistas semiestruturadas com voluntários do primeiro período do curso de Pedagogia. A análise do conteúdo indica que a escolha profissional do Pedagogo é influenciada por uma visão ingênua e fatalista sobre a sua condição no mundo,
\end{abstract}


revelando uma visão de intervenção pautada nos cuidados maternos. Identificamos que os pedagogos entrevistados são pessoas que buscam ideais enraizados em práticas, sentimentos, valores e princípios familiares trazidos pela Igreja Católica desde os primórdios da história, em busca de uma ocupação profissional que os permitam alcançar a estabilidade financeira por meio de concurso público.

Palavras chave: escolha profissional; pedagogia; expectativa

\begin{abstract}
:
This research turns to the professional choice of Pedagogy academics in order to know how this choice is given and what the expectations of these students are regarding their insertion in the market. It is intended to problematize on the constitution of a professional identity committed to the pedagogical actions. This is an exploratory qualitative research whose data were collected through fifteen semi-structured interviews with volunteers from the first period of the Pedagogy course. Content analysis indicates that the Pedagogist's professional choice is influenced by a naive and fatalistic view of her condition in the world, revealing a vision of intervention based on maternal care. We identify that the interviewed pedagogues are people who seek ideals rooted in practices, feelings, values and family principles brought by the Catholic Church since the dawn of history, in search of an occupation that would achieve financial stability through public tender.
\end{abstract} Keywords: professional choice; pedagogy; hope

\title{
Resumen
}

Esta investigación se convierte en la elección profesional de los académicos de Pedagogía para saber cómo se da esta elección y cuál es la expectativa de estos estudiantes con respecto a su inserción en el mercado. Se trata de problematizar en la constitución de una identidad profesional aceptada a las pedagogical actions. Esta es una exploración cualitativa de investigación cuya fecha se ha recopilado a través de la mitad de la mitad de la semivación de la entrevista con los voluntarios del primer período del Pedagogy course. El análisis de contenido indica que la pedagogía de la elección profesional está influenciada por la nativa y fatalista de la condición en el mundo, revisando la visión de la intervención basada en el cuidado materno. En el caso de la Iglesia Católica, la Iglesia Católica es una de las más antiguas del mundo.

Palabras clave: profesional choice; pedagogy; esperanza

\section{Introdução}

Conhecer a escolha profissional dos acadêmicos do curso de Pedagogia, é um tema é significativo, uma vez que possibilita pensar e refletir sobre os cursos formadores de profissionais de educação e em programas de orientação profissional, promovendo o esclarecimento da atuação responsável e profissional no mercado de trabalho. A problemática da transição dos estudantes tem sido uma preocupação de muitos pesquisadores, como Nóvoa (1999), Arroyo (2000) Pimenta (2000, 2005) que se preocupam com as características deste profissional que estarão atuando nas escolas.

Ao falar do professor e sua identidade é preciso resgatar a história da profissão. O período de predominância da Pedagogia vai dos jesuítas até os anos que precedem o 
Movimento dos Pioneiros da Educação Nova. Período em que o estudo da Educação se faz a partir da ideia da unicidade da Pedagogia influenciada pela Igreja Católica, depois pelos moldes herbatiano e positivista. Johan Friedrich Herbart (1776-1841) foi o precursor de uma Psicologia experimental aplicada à Pedagogia. Foi o primeiro a elaborar uma Pedagogia que pretendia ser uma ciência da educação. Somente uma Pedagogia unitária poderia formular um sistema de conceitos em torno dos fins e métodos da educação: o homem em formação. (Pimenta, 2000, 2005).

$\mathrm{Na}$ segunda metade do século XVIII, a Europa procurava esboçar o perfil do professor ideal, que estava muito ligado ao controle da Igreja. Nesse século, houve a estatização do ensino, substituindo o corpo de professores religiosos por um corpo de professores sob o controle do Estado, com mudanças significativas nos valores originais da profissão docente (Nóvoa, 1999). A gênese da profissão de professor tem lugar no seio de algumas congregações religiosas, os jesuítas foram progressivamente moldando saberes, técnicas e normas de valores específicos da profissão (Nóvoa, 1999).

A Pedagogia surge em uma relação ambígua posto que saberes e técnicas foram quase sempre produzidos por vários especialistas. Nóvoa (1999) diz que "a natureza do saber pedagógico e a relação dos professores ao saber constituem um capítulo central da história da profissão docente" (p. 16). Os professores aderem a uma ética e a um sistema normativo essencialmente religioso; mas, mesmo quando a missão de educar é substituída pela prática de um ofício e a vocação cede lugar à profissão (Nóvoa, 1999) Na virada do séc. XIX para o séc. XX, muitos indivíduos começaram a dedicar-se ao ensino como uma ocupação principal, exercendo-a em tempo integral.

Na metade do séc. XIX, a profissão professor fixa uma imagem intermediária, em que os indivíduos são vistos entre várias situações não são burgueses, mas também não são povo no entanto têm uma influência importante nas comunidades. Outro aspecto é a associação da profissão docente ao sexo feminino que deve-se ao fato da expansão das Escolas Normais ter ocorrido em um período em que a mulher era "destinada" às tarefas domésticas e educativas. Assim, à docência era aceita como uma das poucas atividades extra domésticas adequadas para as mulheres, ainda, que, segundo Rêses (2008), o número de professores do sexo feminino foi significativamente maior do que os do sexo masculino, devido à identidade feminina, pois se acreditava que as mulheres poderiam realizar muito melhor essa tarefa. 
Essas ideias ainda se encontram presentes nos dias de hoje, contudo é preciso aprofundar ou desconstruir algumas ideias em torno desse processo de feminização, para não simplesmente justificá-lo como decorrente das características próprias da mulher. Porque masculino/feminino não são entidades isoladas ou pré-determinadas pela cultura, parte-se do pressuposto "de que as identidades são socialmente construídas pela alteridade" (Sayão, 2005, p. 46).

A função da professora é desqualificada como prática e saberes especializados e é concebida como continuação das tarefas da primeira educação, próprias da mãe. A própria denominação "tia", reforça a proximidade e identificação da professora com figura familiar e similar à materna (Freire, 1997). O conceito de feminização do magistério não se refere apenas à participação maciça de mulheres nos quadros docentes, mas também à adequação do magistério às características associadas ao feminino (Louro, 1997; Carvalho, 1996). A primeira Escola Normal foi criada em Niterói, Rio de Janeiro, no ano de 1835. Objetivando formar professores para atuarem no magistério de ensino primário. Desde então, a criação de Escolas Normais esteve marcada por diversos movimentos de afirmação e de reformulações, que atravessou a República e chegou aos anos 1940/50 como instituição pública fundamental (Villela, 1992). Nesse período, os professores eram contratados por seu prestígio social e político e não por sua formação. Nessa época, para exercer o magistério não era necessária a formação do professor. Isso ocasionou pouca procura pelo curso.

Na década de 1920, várias reformas de ensino foram realizadas, trazendo um novo significado para a prática docente, pois foi atribuída ao professor a tarefa de formar as crianças e os jovens para a vida e para a promoção de desenvolvimento econômico, social e cultural (Romanowski, 2007). O modelo criado em 1920 perdurou até os anos de 1970 e no início dos anos de 1990, o curso de Pedagogia passou a ter a docência como eixo articulador do processo de formação. Atualmente, a formação do professor de educação infantil coincide com a formação do Pedagogo.

A formação do Pedagogo Escolar no Brasil está atualmente inserida no curso de Pedagogia regulamentada pela Resolução CNE/CP Nº.1, de 15 de maio de 2006, que determina uma carga horária mínima de 3.200 horas, sendo oferecido em instituições superiores nas formas presencial, semipresencial ou à distância. Contempla a formação do docente e a formação dos profissionais da educação em uma mesma graduação, entretanto, Libâneo (2005), Nóvoa (1999) e Pimenta (2005), criticam que a disposição do 
curso não está satisfatória. Defendem que deverá existir um curso para formar docentes e outro para formar profissionais da educação. Libâneo (2005) e Pimenta (2005) são claros ao afirmar que a formação do Pedagogo vai além da docência. Abrange a pesquisa, a documentação, a formação de profissionais, a gestão e coordenação de sistemas escolares, entre outros conhecimentos.

Uma visão mais adequada para os dias de hoje, seria da formação do Pedagogo com base no tripé: docência, gestão e pesquisa, na linha do parecer do Conselho Nacional de Educação (CNE) para o Curso de Pedagogia (CP), o CNE/CP n ${ }^{\circ}$ 5/2005. Desse modo, a Pedagogia superaria uma formação fragmentada, unilateral e tecnicista e voltaria a abraçar sua tradição de visão global simbolizada na coruja, ícone do curso. Visando à formação de professores para o ensino normal e de especialistas para as atividades de orientação, administração, supervisão e inspeção no âmbito das escolas e dos sistemas escolares. (Carvalho, 2014).

$\mathrm{Na}$ formação dos professores existe uma importante dificuldade em conseguir gerar uma boa ligação entre a teoria e a prática. Busca-se discutir, então, quais são as expectativas dos alunos do curso de Pedagogia ingressantes no que diz respeito à atuação na docência e compreender a busca desta profissão. A psicologia hoje não pode furtar-se a pensar o mundo e a subjetividade como inserida em uma sociedade global. O processo de globalização tem trazido novos componentes que ampliam e problematizam discussões em torno de conceitos, modos de vida e profissionais. O acesso à informação de forma acelerada e múltipla, as mudanças sociais, econômicas e culturais do mundo contemporâneo provocam alterações e muitas vezes desconcertantes na forma, que nos leva a dúvidas, incertezas e ao imediatismo.

Desde o final do século XX, até o limiar do século XXI, as ciências sociais como um todo, passaram a lidar com um novo objeto de estudo, a sociedade globalizada, onde as relações de escala mundial têm preeminência sobre as relações de escala nacional. Simultaneamente às forças que operam no sentido da articulação, integração e até mesmo homogeneização, operam forças que afirmam e desenvolvem não só as diversidades, singularidades ou identidades, mas também hierarquias, desigualdades, tensões, antagonismos. São forças que alimentam tendências integrativas e fragmentárias, compreendendo nação e nacionalidade, grupo e classes sociais, provincianismo e regionalismo, localismo e cosmopolitismo, capitalismo e socialismo. (Ianni, 1994, p. 156) Esse contexto desempenha papel fundamental na constituição das subjetividades. A 
construção da subjetividade tem caráter dialético. É constituída pelos sentidos que os sujeitos dão às suas experiências no mundo e também pelos significados apropriados dos discursos que o mundo complexo globalizado oferece por meio da fluidez da informação. Esse contato com discursos diversos e novos não implica, entretanto, uma abertura para o diferente. (Mancebo, 2002),

No final da década de 1980 e início de 1990, a situação brasileira em relação às mudanças na economia, trouxeram um ponto importante quanto à adequação dos recursos humanos às novas exigências do mercado de trabalho: referente a educação geral, nesse novo cenário econômico, ela se desestruturou, em função do aumento da competitividade exigida pela abertura da economia, pela exigência de novas formas de produção (chamada de Terceira Revolução Industrial) (Fogaça, 2006). Diante desse quadro, uma reforma da educação geral seria pertinente, começando por uma revisão das estratégias tradicionais de qualificação profissional. Penna Soares e Sestren (2007), afirmam que o mercado de trabalho, atualmente, também pode ser caracterizado por grandes mudanças decorrentes da globalização e dos avanços tecnológicos. Segundo Dias (2009), a questão da formação profissional nos leva a refletir sobre as possibilidades ou não de os universitários virem a conseguir trilhar um caminho de inserção ocupacional que permita o desenvolvimento de melhores condições de vida na contemporaneidade.

O ensino superior tem figurado como tema polêmico e vem suscitando uma série de questionamentos e reflexões sobre o papel da universidade na formação de profissionais habilitados a lidar com a complexidade dos desafios que emergem com maior frequência na sociedade contemporânea. Embora a globalização continue a ser básica, indispensável e presente em âmbito internacional, ela é original, desconhecida e carente de interpretações suscitando mudanças no modo de viver e formas de trabalhar. Gondim (2002) sintetiza o conjunto de transformações pelas quais a sociedade da informação vem passando em diferentes esferas, entre as quais, a esfera cultural. A diminuição da distância entre o desenvolvimento científico e sua aplicabilidade prática modificou a visão de mundo que define valores temporais e morais.

A escolha profissional configura-se como fenômeno multideterminado socialmente. Em sua problemática, transitam fatores de ordem pessoal, familiar, cultural, econômica, educacional, de gênero e outros discursos que têm origem nas diversas relações que compõem a rede social em que o sujeito se insere. "O homem é um ser ativo, social e histórico". (Bock, 2001) Em relação ao profissional da Educação, as pressões 
exercidas junto a esses, têm gerado muitas inquietações, principalmente sobre as responsabilidades atribuídas ao educador, questões salariais, condições de trabalho e plano de carreira. Essas inquietações e outros discursos fazem parte das mediações que estão presentes na formação do pedagogo. A escola é atravessada por essa contradição e, portanto, nosso objetivo foi pensar a escolha profissional das acadêmicas de pedagogia enquanto atravessada por uma identidade profissional relacionada à construções sociais sobre o masculino e o feminino.

\section{Método}

É a partir do método que todo estudo se viabiliza e se direciona para alcançar os objetivos aos quais se propõe, conforme Costa (2002) e Alves-Mazzotti (1991), (Teo, 2015). As pesquisas refletem pressupostos de ordem ontológica e epistemológica, a psicologia crítica, compreende o indivíduo em seu contexto social, cultural e histórico. Dentro dessa perspectiva, o método qualitativo conforme Haguette (2001) e Chizzotti (2005), Minayo (1994), enfatiza as particularidades de um fenômeno, demonstrando uma relação dinâmica entre o mundo real e o sujeito. Para o método qualitativo se preocupa com um nível de realidade que não pode ser quantificado, abrangendo, desse modo, um universo de significados, motivos, aspirações, crenças, valores e atitudes, cujo objetivo segundo Bodgan e Biklen (1994) é melhor método para compreender o comportamento e as experiências humanas. Após projeto de mestrado ser avaliado positivamente pelo Comitê de Ética sob o número 16085978, a pesquisadora entrou em contato com alunos das faculdades pertencentes a sua rede de contato via internet, facebook com adesão voluntária. Através do aceite do Termo de Consentimento Livre e Esclarecido foi realizada uma entrevista semiestruturada de aproximadamente uma hora de duração, individualmente e de acordo com a disponibilidade de cada um. A entrevista foi gravada e transcrita para avaliação posterior, após a transcrição da entrevista os dados foram descartados.

Os dados foram analisados a partir da análise de conteúdo dentro de uma perspectiva crítica, ou seja, desnaturalizando o objeto de estudo a partir de um olhar histórico. A análise compreendeu uma leitura cuidadosa, que caminhou entre o texto (entrevista escrita), o contexto social, a identificação e a localização das matrizes ideológicas marcadas pela história. Assim, examinamos o conteúdo, organização, função 
do discurso e identificamos os temas expressos em relação à escolha e às expectativas de futuro profissional, bem como a presença ou não de projetos de vida profissional. A finalidade da análise foi fundamentada em uma argumentação detalhada e sustentada pelo dado empírico expresso e revelado na fala dos entrevistados.

\section{Análise e discussão}

Com o objetivo de conhecer a escolha profissional dos acadêmicos do curso de Pedagogia, identificando suas expectativas quanto à inserção no mercado de trabalho conseguiu-se identificar os seguintes indicadores temáticos: 1. Motivo da escolha associado a uma idealização da profissão, 2. Motivo da escola associado a uma visão ingênua, 3. Motivo da escolha associado a uma fatalista, 4. Expectativa profissional, 5. O projeto de vida.

1. Motivo da escolha associado a uma idealização da profissão

Sobre o motivo da escolha em que ocorre uma idealização da profissão, sobre a qual podemos dizer que os acadêmicos de Pedagogia possuem uma imagem ingênua em sua prática e não veem a si mesmos como profissionais, mas como pessoas que gostam, amam, acham lindo o que fazem. Como expressam nestas falas:

Entrevista 2: "Escolhi o curso de Pedagogia, primeiramente por que amo crianças, me dou bem com elas e me sinto bem também."

Entrevista 4: "A professora Hilda, nome da minha professora, dava aula e brincava como uma segunda mãe. E daí eu resolvi ser professora".

Entrevista 5: "Escolhi Pedagogia, por amor, pois amo estar junto de crianças."

Entrevista 9: "Escolhi Pedagogia, justamente para poder trabalhar com crianças.

Entrevista 10: "...adoro crianças."

Entrevista 11: "Escolhi fazer Pedagogia porque tenho amor pelas crianças..."

Entrevista 12: “...por vontade de dar aula. De repente, deu vontade de mudar o quadro que se encontra a educação hoje."

Entrevista 13: “...porque gosto do meio escolar. ... Amo trabalhar com pessoas!”

Entrevista 14: "Como adoro crianças e sei que com este curso posso ajudá-las, estou muito feliz."

Entrevista 15: "por gostar de lidar com pessoas, principalmente crianças."

O pensar sobre este grupo de pedagogas inicia-se em considerar o seu pertencimento de classe no qual as expressões de amar o meio escolar, do cuidar e gostar se faz como um sentir-se parte de uma coletividade. A identidade reflete a necessidade 
de ser único, de ser reconhecido em sua diferença o elemento eu gosto, eu adoro reflete a emocionalidade presente na motivação em um ideal de profisssão.

Todos esses elementos é que delineiam a identidade dos pedagogos entrevistados que vivem em nossa sociedade nos tempos atuais mas que refletem uma noção sobre a infância que remonta ao século XVIII. Para Ariès (1973), as crianças continuam sendo vistas apenas como seres biológicos que necessitam de grandes cuidados, com o objetivo de transformá-las em adultos socialmente aceitos corroborando visões de outros autores sobre o pedagogo como Levin (1997), Narodowski (1993), De Mause (1991) e Rousseau (1995). A escola continua sendo responsável por uma visão da infância ingênua e delimitada pelo ciclo escolar sem considerar ainda que outros se "transformam" em adultos sem ter condições para isso (crianças de rua, trabalho infantil, etc). A identidade do pedagogo vai se configurando no mesmo movimento da configuração histórica da infância. A infância não é um simples conceito, é um preceito, um projeto de ser, vinculado a ideais de felicidade e emancipação (Phillipe Ariès, 1973). Além dessas concepções, outros fatores também contribuem para a escolha do curso de Pedagogia.

2. Motivo da escolha em que ocorre uma visão ingênua

O motivo da escolha se embasada em raízes familiares e sonhos (sentimentos), que perpassam uma visão não só ingênua como fatalista da realidade. A identidade profissional se relaciona com um sistema de ideologias internalizado a partir das experiências cotidianas com o mundo social. As falas abaixo serão analisadas com base em Álvaro Vieira Pinto (1960) e Martín-Baró (1998), que caracterizaram uma determinada visão de mundo e de realidade baseada em sentimentos sobre uma profissão, como "visão ingênua" e "visão fatalista".

Entrevista 1: "Os motivos para cursar uma faculdade é me destacar no mercado de trabalho, se aperfeiçoar, ter uma profissão definida, melhorar de vida."

Entrevista 2: "Faço uma faculdade para me tornar alguém, ter uma profissão digna no futuro e ter orgulho no dia que receberei meu diploma."

Entrevista 3: "Escolhi o curso de Pedagogia porque gostaria de fazer alguma coisa que fizesse a diferença para alguém, atuar na área da educação, se atuar da forma certa, pode mudar a vida de muita gente."

Entrevista 4: "Quero cursar uma faculdade por que penso no futuro, preciso de alguma coisa que me dê base para eu ter um futuro melhor, um pouco mais tranquilo."

Entrevista 8: "Escolhi Pedagogia por incentivo da minha mãe."

Entrevista 9: "Quem me influenciou muito e me incentivou foi minha filha." 
Entrevista 10: "Quero uma faculdade para obter sucesso no futuro, crescer na vida e ganhar bem."

Entrevista 11. “...para melhorar de vida, ter um conhecimento e dar orgulho aos meus pais."

Entrevista 12. “...preciso ter um diploma, ter uma profissão.”

Entrevista 14: “...para poder ter um curso superior e poder ter um emprego bom.” Entrevista 15. “...por querer melhorar a vida, pois hoje não é suficiente só o segundo grau..."

Ao considerar a natureza heterogênea do mundo em que vivemos e que se reproduz discursos múltiplos, as pedagogas nos revelam motivações heterogêneas em que as narrativas do sucesso, dos incentivos familiares influenciam suas escolhas profissionais tanto quanto o ser alguém e o melhorar na vida. $\mathrm{O}$ mundo da pós modernidade reproduz e produz universos discursivos tão numerosos quanto os mundos sociais, ou grupos sociais, que contém. (Clarke, 2014).

Os conteúdos do discurso do grupo social formado pelos alunos de pedagogia revelam motivos ingênuos da escolha profissional, que se caracteriza pela estreiteza de horizontes conceituais, a partir dos quais se interpreta o mundo em que o sujeito se insere. A visão ingênua é catalisadora e configuradora de visões deificadas, naturalizadoras de valores, hábitos e costumes vigentes de tempos imemoriais que se apresentam como formas de pensamento e ação (Vieira Pinto, 1960). A consciência ingênua particulariza a interpretação da realidade e a submete a julgamentos de valores a partir de princípios tomados como válidos. A consciência ingênua articula-se sobre a crença de que a realidade do mundo e da existência em sua totalidade se apresenta estática, imóvel, eterna. Para o ingênuo, a realidade é vista de forma absoluta, emoldurada e imediatista nas relações onde se inserem os seres humanos.

3. Motivo da escolha em que ocorre uma visão fatalista

As motivações da escolha da pedagogia se relacionam com uma concepção fatalista que transforma os acontecimentos sociais em fenômenos naturais cuja alteração é improvável. O fatalismo é uma realidade social extrema e objetiva antes de se converter em uma atitude pessoal interna e subjetiva. Para o indivíduo pertencente à classe social, cuja moradia encontra-se nas periferias das cidades, aprende, no dia a dia, qual é o seu lugar na sociedade e que seus esforços, possivelmente, não produzirão transformações 
essenciais na sociedade, marcada pela exploração e opressão (Martín-Baró ,1998). Como expressam suas falas:

Entrevista 1: “... acredito que a educação é a base de tudo... e por acreditar que sem educação não somos nada, fez com que eu escolhesse a Pedagogia."

Entrevista 2: “...e por eu ter orgulho da minha mãe e tê-la como inspiração. Ela é professora há tantos anos e ela gosta do que faz. Quero ter essa mesma satisfação.."

Entrevista 3: "Sou a primeira da minha família a entrar para um curso superior."

Entrevista 4: “.... Primeiro porque gaguejo e por causa disso nunca vou poder dar aula e segundo porque vou morrer de fome.

Entrevista 7: "Minha mãe não quer que eu siga a mesma profissão dela, pois diz que é uma profissão não valorizada, ganha pouco e trabalha e incomoda muito.

Entrevista 8: “...estava saindo do Ensino Médio, tinha que fazer alguma coisa, mas não tinha ideia do que."

Entrevista 9: “. É preciso ter perseverança e confiar em Deus, colocar Ele em primeiro lugar em tudo

Entrevista 10: "Quero uma faculdade para obter sucesso no futuro, crescer na vida e ganhar bem. Penso que, para isso, tenho que fazer concurso público.”

Entrevista 11: "fazer vestibular e cursar uma faculdade para melhorar de vida, ter um conhecimento e dar orgulho aos meus pais."

Entrevista 13: "As decisões difíceis que tomei até hoje foi abrir mão de ficar mais tempo com meu filho e estudar. Estou estudando para que futuramente eu possa dar uma vida confortável para ele, meu filho.”

Sobre o fatalismo, as expressões "eu tinha que fazer, eu tenho que fazer alguma coisa" e crenças como "a educação é a base de tudo" revelam a obrigação o ter que fazer talvez como única opção da vida para alguns dos sujeitos entrevistados. Segundo MartínBaró (1998), podemos dizer que é um esquema ideológico, que se origina nas estruturas sociopolíticas e se enraíza psiquicamente, garantindo, desse modo, a reprodução da dominação social e a manutenção da ordem estabelecida. É um valioso instrumento ideológico que induz à aceitação da realidade social, gera comportamentos dóceis e estimula a resignação diante das exigências da vida. Para Vieira Pinto (2012), essa postura em torno da qual se constitui a consciência ingênua conduz ao dogmatismo de posições e visões de mundo. Num segundo momento, essa lógica manifesta-se em formas pessimistas e catastróficas em relação às possibilidades humanas no presente.

Identidade do professor não aliado ao pertencimento de classe.

A configuração da identidade do professor na história da educação brasileira remete a múltiplas ambiguidades construídas ao longo dos últimos anos. Falar em 
identidade sob a perspectiva antropológica é falar primordialmente em cultura, pois a cultura encontra-se assim mais dominada do que nunca pela problemática da identidade, que se enuncia cada vez mais como uma "identidade cultural" (Agier, 2001, p.7). O quer dizer que, quando falamos de identidade devemos levar em conta os variados pertencimentos do sujeito: o nacional, o regional, o social, o cultural, o étnico, envolvendo suas relações, seus valores, suas crenças, sua língua (Agier, 2001). Seu caráter múltiplo e instável deve-se à forma contextual e relacional com que tem sido socialmente construído nos últimos anos, ou seja, os processos identitários não existem fora do contexto.

Entrevista 5: "Estou cursando agora uma faculdade, além do financeiro..."

Entrevista 8: "Minha decisão séria que tive que tomar até hoje foi trancar minha faculdade o ano passado, pois não tinha dinheiro para pagar. Este ano, estou tentando novamente e pretendo não parar mais, pois não se consegue nada fácil. Temos que pensar a longo prazo."

Entrevista 10: "Fiz vestibular, assim que saí do Ensino Médio para Serviço Social. Parei por que era muito alta a mensalidade. Então resolvi fazer Pedagogia, pois além da mensalidade ser mais em conta, adoro crianças."

Entrevista 13: “..., mas a mensalidade da faculdade cabe bem no meu bolso.” Entrevista 15: "Escolhi Pedagogia por ser mais barato e..."

A opção por definirem-se como professores se relaciona com condições financeiras dos trabalhadores em educação. A preocupação por encontrarem-se como profissionais competentes em um campo do conhecimento vai e volta e reflete a procura da identidade coletiva e pessoal. Há profissões que têm seu estatuto definido e reconhecido. Isso fortalece a identificação como profissionais. Entretanto, o saber-fazer dos professores de Educação Básica ainda não tem seu estatuto profissional. O discurso do profissionalismo é um sonho ambíguo. Do lado da categoria, pode significar o reconhecimento e a valorização. Do lado social, pode significar a justificativa para adiar esse reconhecimento, ou seja, são os níveis de titulação que servem como base para o reconhecimento e valorização. "Somos a imagem que fazemos de nosso papel social, não o que teimamos ser”. (Arroyo, 2000, p. 29) Esses profissionais querem conseguir que os outros acreditem no que são. Um processo social complicado, lento, de desencontros entre o que são para eles mesmos e o que são para fora. É a imagem social que foi construída sobre o ofício de mestre, sobre as formas diversas de exercer esse ofício que prevalece.

Segundo Arroyo (2000), existe uma insegurança expressa quando esses profissionais saem da graduação e vão para o Mercado de trabalho e são "engolidos" pelo sistema posto pelos profissionais que estão a mais tempo no exercício, indo de encontro 
ao subsolo educativo, ou seja, as práticas rotineiras não planejadas, diluídas no ambiente escolar. Falta uma conscientização de assumir essas funções de subsolo, "quaseeducativas" como educativas, formadoras e deformadoras. Preparamos aulas, vamos para a escola cada dia para capacitor seres humanos para irem além de suas predisposições inatas.

\section{Expectativa Profissional}

A partir do momento em que a história da educação foi-se configurando nos setores públicos e populares, consolidou a marca da formação dos professores, principalmente da educação básica: a maioria dos professores e professoras têm como origem as camadas médias baixas. Essa tendência vem dos primórdios da instrução primária e se afirma nas últimas décadas. Salário de professor(a) nunca foi para filho(a) de quem tem posses e dinheiro (Arroyo, 2000). Com base nessa afirmação, pergunta-se: será que a escolha ou opção pelo magistério ou pedagogia tem a ver com a condição social? O que leva à escolha da profissão de pedagogo? Arroyo (2000) nos diz que a imagem que possuímos como categoria, as características sociais que definem a escolha por esta profissão, têm a ver com os limites materiais e culturais da origem social a que a maioria pertence.

A herança cultural e social tem influência nas aspirações profissionais, na socialização. Ser professor(a) projeta uma determinada função social, e, mais do que isso, projeta ou concretiza uma determinada cosmovisão que está incorporada a esse ofício. A condição de vida está presente em nossas escolhas ou condiciona nossas escolhas.

Entrevista 1: “...sentia a necessidade de prosseguir meus estudos, escolhi tal curso. Pretendo, ao sair da faculdade, atuar na área com o ensino público e iniciar a pós graduação."

Entrevista 2: “... ter uma profissão digna no futuro e ter orgulho no dia que receberei meu diploma." "Minhas expectativas é que a gente faça a diferença na vida dos alunos ou que um dia lembre que eu fiz algo que marcou na vida dela, que eu consiga suportar as dificuldades no trabalho, pois sei que é difícil, muitos anos lidando com crianças cansa mentalmente e emocionalmente."

Entrevista 3: "Sou a primeira da minha família a entrar para um curso superior." Entrevista 4: "Quero cursar uma faculdade porque penso no futuro, preciso de alguma coisa que me dê base para eu ter um futuro melhor, um pouco mais tranquilo."

Entrevista 5: "Estou cursando agora uma faculdade, além do financeiro..."

Entrevista 6: "... para ter mais oportunidades de trabalho."

Entrevista 7: "Estou fazendo uma faculdade para ter uma profissão." 
Entrevista 9: "Quero fazer uma faculdade para me preparar melhor para o mercado de trabalho, ter estabilidade financeira..."

Entrevista 10: "Quero uma faculdade para obter sucesso no futuro, crescer na vida e ganhar bem. Penso que para isso, tenho que fazer concurso público."

Entrevista 11: "Resolvi então, fazer vestibular e cursar uma faculdade para melhorar de vida, ter um conhecimento e dar orgulho aos meus pais."

Entrevista 12: “...pretendo fazer uma pós e tentar concurso público.”

Entrevista 13: "Estou fazendo uma faculdade por querer uma estabilidade profissional. Quero, assim que terminar o curso, prestar concurso público..."

Entrevista 14: "Quero fazer uma faculdade para poder ter um curso superior e poder ter um emprego bom."

Entrevista 15: "Voltei a estudar por querer melhorar a vida, pois hoje não é suficiente só o segundo grau. Escolhi Pedagogia por ser mais barato..."

A posição familiar marcada pela posição de classe ou expressão concreta da condição de classe tem uma projeção decisiva, não apenas na socialização, que acontece nas relações familiares, mas na socialização posterior, em outras instâncias como a rua e a escola. A autoimagem familiar e de classe social está presente na escolha da escola pública ou privada, cujas imagens perpassam pelo ensino de boa ou má qualidade, ou seja, perpassam pela autoimagem social que, em determinadas profissões se estabelece sobre os valores e traços que as definem. Na visão ingênua, para as famílias, ser professor é uma profissão que envolve princípios e valores religiosos, tradicionais, que toda mulher deve ter.

Entrevista 1: "Tive influências para escolher fazer Pedagogia. Minha sogra é professora e, vendo o trabalho que ela desenvolve, o amor que tem pela profissão, e por acreditar que sem educação não somos nada, fez com que eu escolhesse a Pedagogia."

Entrevista 2: "Minha mãe só me deu uma ideia. Lembro dela falando: se você gosta de crianças, você se dará bem em Pedagogia."

Entrevista 3: "Uma das decisões mais sérias que tive que tomar na vida, foi tomar a decisão de fazer o curso de pedagogia, contra toda minha família, contra tudo que minha família diz. Primeiro por que gaguejo e por causa disso nunca vou poder dar aula e segundo pro que vou morrer de fome." "A professora Hilda, nome da minha professora, dava aula e brincava como uma segunda mãe. E daí eu resolvi ser professora."

Entrevista 6: "Minhas filhas e o trabalho que influenciaram muito para tomar a decisão de voltar para a faculdade e fazer Pedagogia."

Entrevista 7: "Escolhi Pedagogia, pois nasci neste meio: minha mãe é professora. Acho muito legal e instigante pelas coisas que ela faz e conta."

Entrevista 8: "Escolhi Pedagogia por incentivo da minha mãe." 
Entrevista12: "Minhas amigas que fazem e estão se formando em pedagogia e já dão aula foram a que me influenciaram para eu fazer esse curso. Elas me mostram o universo mágico de dar aula.

Entrevista 14: "Minha irmã é educadora há 20 anos e ela e meus filhos me incentivaram para fazer uma faculdade e fazer Pedagogia."

Ninguém deve optar por um determinado trabalho apenas por ser possível para sua condição social. A escolha deve-se dar por um processo de tentativa de identificação com esse papel que vai desempenhar, que poderá acarretar em um peso leve ou pesado, ou, muitas vezes, chegar a uma realização profissional. É um modo de vida, de dever ser, que tenciona todas as dimensões, tempos, vivências e lembranças.

\section{Projeto de Vida}

Está relacionado com a continuidade da existência do sujeito, um vir a ser, uma perspectiva de futuro. Segundo Dias (2009), etimologicamente, a palavra projeto de vida deriva do latim, projectus, algo como um jato lançado para frente, relacionando com uma abertura (não determinação) para o futuro (antecipação). Para D’Angelo Hernández (2000), a noção de projeto de vida aponta para uma realidade constitutiva da pessoa e da coletividade, se configura dinamicamente nos planos e nas possibilidades, na articulação dos mecanismos psicológicos da realidade (subjetividade e prática) em suas dimensões temporal e social, em sua historicidade e contextualização cultural.

Entrevista 3: "Não penso em metas da minha vida, ou seja, não tenho pronto um projeto de vida. Mas, todos os dias, pelo menos uma vez a cada semestre paro para repensar os meus projetos. Agora, na faculdade, penso nas metas no começo e fim de cada semestre porque temos mais acesso a informação e sempre aparecem novidades e novas áreas dentro da pedagogia que eu possa me interessar."

Entrevista 4: "Geralmente penso no meu futuro, nas minhas metas, todos os dias, no banho. Fico uma meia hora pensando se estou no rumo certo, to fazendo a coisa certa."

Entrevista 5: "Atualmente tenho pensado muito nas minhas metas e nos meus objetivos de vida. Tenho uma filha para criar."

Entrevista 6: "Penso pouco nas metas da minha vida, mas quando penso, por necessidade, vou até o fim." ... "Penso nas possíveis dificuldades, assim que terminar o curso, sendo a questão financeira, ou melhor, não dificuldade, mas que irá melhorar."

Entrevista 7: "Penso se isso mesmo que quero."

Entrevista 8: "Penso muito, tenho projetos de vida para o meu futuro." 
Entrevista 9: "Penso muito no meu futuro e com o diploma, pretendo fazer um concurso público. Sei e já estou passando por dificuldades, mas estou me sentindo confiante e determinada, pois nada em nossa vida vem fácil."

Entrevista 10: "Penso todos os dias em minhas metas para o futuro, inclusive em não desistir da faculdade."

Entrevista 12: "... penso mito em minhas metas e o que quero para o futuro".

Entrevista 15: "Tenho metas para minha vida, mas ainda não sei o que fazer depois de formada ..."

Gondim (2002) destaca duas conclusões em relação ao projeto de vida: 1) não há clara definição do perfil profissional exigido no mercado de trabalho, o que prejudica a elaboração de planos futuros mais definidos; e 2) o despreparo profissional está relacionado à qualidade dos estágios curriculares, avaliados como insuficientes e inadequados, o que compromete tanto o perfil profissional, quanto a inserção num mercado que coloca em xeque os limites rígidos entre alguns campos de atuação prática. Como corroboram autores como Fogaça (1998), Fiori (1998); Scherer, (1997), Leite, (1996); Salerno, (1994), tornando quase impossível ignorar a confluência entre as organizações educacionais, as empresas e a comunidade (Dowbor, 1996).

\section{Considerações Finais}

Pensando a Educação se encontra hoje, principalmente no que diz respeito à educação formal, tanto no âmbito do ensino fundamental, como no médio e superior, surgiu a necessidade de conhecer porquê os jovens escolhem o curso de Pedagogia e qual as suas expectativas na inserção no mercado de trabalho. Não escolhemos a profissão que queremos, mas a possível. Essa condição está presente na socialização de toda nossa vida, sobretudo de nossa infância e juventude, na socialização das imagens profissionais e das posições que projetamos como possíveis. As camadas populares, médias baixas, vão internalizando, socializando a imagem de professor como possível, a seu alcance, e como a única alternativa de saída. Essa realidade social, a incorporação e aceitação dos valores, do estilo de ser professor(a) é que vão sendo aceitos, internalizados desde cedo e que vão conformando a identificação de vida, de universo cultural, a representação social e cultural do magistério.

A formação de professores no Brasil está muito confusa e as perspectivas de possuir professores que acompanhem e ajam de acordo com a evolução e mudança 
avassaladora, advinda da globalização, tanto na área tecnológica, como psicológica, englobando pensamentos, comportamentos, está difícil, por existir como pano de fundo uma história enraizada em princípios e valores fundamentados na igreja e em práticas instrumentais que muitas vezes bloqueiam o senso crítico e a paisagem que norteia os dias atuais.

São professores com pensamento do século XVIII: autoritários, donos do saber. Pensamento e postura advinda dos jesuítas quando catequizaram os índios. E dos colonizadores. Exatamente o que enfrentamos em muitas escolas e universidades: professores catequizando seus alunos. Esta postura se arrasta pelos séculos. Com a revolução industrial, a profissão professor passou a ser considerada muito mais para mulheres do que para homens, pelas características tidas como próprias delas como meiguice, carinho, senso materno. Características próprias que toda criança precisaria. "Sendo incapaz de refletir sobre si mesma e alcançar os pressupostos que a sustentam, a consciência ingênua é vítima da ilusão de julgar-se incondicionada." (Vieira Pinto, 1960, p. 87).

A criança era e ainda é percebida como um ser que necessita de cuidados e não de um professor e uma escola que lhes transmita conhecimentos. Já os homens, não possuindo as características maternais femininas, afastaram-se desta profissão indo em busca de novos empregos e de oportunidades com salários mais altos. Afirmações fundamentadas por Libâneo (2005), Pimenta (2005) e Nóvoa (1999), que sustentam a visão histórica do Pedagogo no Brasil.

Foi possível identificar no discurso dos alunos calouros do curso de Pedagogia, de duas faculdades localizadas em um bairro da periferia da cidade de Curitiba, os motivos que os levaram a escolher este curso para sua formação profissional e quais suas expectativas quanto à inserção no mercado de trabalho. Importante lembrar que os discursos foram produzidos a partir de uma entrevista semiestruturada e foram analisados os conteúdos destes discursos referentes aos objetivos da pesquisa, ou seja, muitos aspectos não foram mencionados por se tratar de uma entre inúmeras análises possíveis. Por se tratar de faculdades de um bairro da periferia de Curitiba, são estudantes pertencentes às classes sociais $\mathrm{C}$ e $\mathrm{D}$, imbuídos da visão fatalista que o sociólogo espanhol Martín-Baró (1999) nos descreve e da visão ingênua, como nos relata o filósofo brasileiro, Álvaro Vieira Pinto (1960). 
Observou-se que são discursos reprodutores da ordem social e não são discursos abertos ao questionamento, à crítica, à transformação social do mundo e da sua condição no mundo. São sujeitos que querem alcançar um status sem transformar sua prática, ou seja, são sujeitos que reproduzem comportamentos e pensamentos de uma sociedade que não dá espaço para a constituição de sujeitos reflexivos e autônomos. Estão inseridos em espaços desta sociedade onde os discursos e as práticas são consolidados.

Há uma dificuldade de ter um pensamento crítico, que possibilite a desnaturalização da ordem social, isto é, são sujeitos distantes da criticidade, pois estão imbuídos de seu contexto social, cultural e histórico. Sujeitos esses que estão preocupados em encontrar uma ocupação profissional que os permita alcançar a estabilidade financeira por meio de concurso público, sem ter consciência de que a profissão docente é um trabalho como qualquer outro e que requer atualmente um domínio de conhecimentos científicos e tecnológicos.

É uma profissão que demanda uma visão de homem consistente, tanto do ponto de vista da natureza deste ser que é o homem (ontologia) como do ponto de vista de como esse homem conhece (epistemologia), visão que permeia sua vida e que orienta a sua prática de professor. $\mathrm{O}$ tema da pesquisa possibilitou a reflexão sobre os cursos de formação de professores e a necessidade de programas de orientação na escolha da profisssão que promovam o esclarecimento da atuação responsável e profissional no mercado de trabalho.

A pesquisa contribuiu para conhecer que o curso de Pedagogia tem sido alvo de uma escolha inicialmente sem uma identidade profissional comprometida com o pensarfazer-refletir sobre as ações pedagógicas. Quando o modelo educacional vincula-se mais à consciência ingênua, se afirma na visão estática, fragmentada, submetida a juízos de valor moral da realidade. Sob essas condições, projetam nas lideranças sua expectativa de mudança, a esperança de dias melhores, a responsabilidade pela resolução de seus problemas, por suas contradições e por seus paradoxos. Creditam toda sorte nos infortúnios, projetando expectativas nas etnias, no clima, no relevo, no passado ou até mesmo no azar os motivos de seu fracasso. A educação formal reproduz esse modelo interpretativo de mundo nas jovens gerações formando um círculo vicioso e promovendo a consciência ingênua e fatalista. 


\section{Referências}

Agier, M. (2001). Distúrbios Identidários em tempos de globalização. Mana-Estudos de Antropologia Social, 7(2). 7-33. Rio de Janeiro, RJ: Programa de Pós-Graduação em Antropologia Social. Museu Nacional Universidade Federal do Rio de Janeiro.

Alves-Mazzotti, A. J. (1991) O planejamento de pesquisas qualitativas em educação. Cadernos de Pesquisa, 77. 53-61.

André, M. (Org.) (2002). Formação de professores no Brasil, 1990-1998. Série Estado do Conhecimento, v.6. Brasília, DF: MEC/INEP/Comp.

Ariès, P. (1973). História social da criança e da família. (2a ed.) Rio de Janeiro, RJ: Guanabara.

Arroyo, M. G. (2000). Oficio de Mestre: Imagens e auto imagens. Petrópolis, RJ: Vozes.

Bock, A. M. B. (1997). Formação do psicólogo: um debate a partir do significado do fenômeno psicológico. Psicologia: Ciência e Profissão [online], 17(2). 37-42.

Carvalho, J. M. \& Simões, R. H. S. (2002). Identidade e Profissionalização Docente: um retrato delineado a partir dos periódicos nacionais. In André, M. (Org.) Formação de professores no Brasil, 1990-1998. Série Estado do Conhecimento, v.6. Brasília, DF: MEC/INEP/Comped.

Carvalho, M. P. de. (1996). Trabalho Docente e relações de gênero. Revista Brasileira de Educação, 2(mai/ago). São Paulo, SP: ANPEd.

Chizzotti, A. (2005). Pesquisa em ciências humanas e sociais. São Paulo, SP: Cortez.

Costa, M. V. (2002). Uma agenda para jovens pesquisadores. In: Costa, M. V. (Org.). Caminhos Investigativos II: outros modos de pensar e fazer pesquisa em educação. Rio de Janeiro, RJ: DP\&A.

D'Angelo Hernández, O. S. (1994). Modelo integrativo del proyecto de vida. Habana, Cuba: Provida II.

D’Angelo Hernández, O. S. (2000). Proyecto de vida como categoria basica de interpretacion de laindentidad individual y social. Revista Cubana de Psicologia, 17(3) 270-275. Havana, Cuba: Centro de Investigaciones Psicológicas y Sociológicas (CIPS). Recuperado de http://www.biblioteca.clacso.edu.ar/ar/libros/cuba/angelo8.rtf em 19 de junho de 2015.

De Mause, L. (1991). História de la infância. Madri, Espanha: Alianza Universid. 
Dias, M. S. D. L. (2009). Sentidos do trabalho e sua relação com o projeto de vida de universitários (Tese de Doutorado não publicada). UFSC, Florianopólis, SC.

Dowbor, L. (1996). Educação, tecnologia e desenvolvimento. In L. Bruno (Org.). Educação e trabalho no capitalismo contemporâneo: leituras selecionadas. (pp.1740). São Paulo, SP: Atlas.

Freire, P. (1997). Professora sim, tia não: cartas a quem ousa ensinar. São Paulo, SP: Olho D'àgua.

Fogaça, A., \& Salm, C. L. (2006). Educação, trabalho e mercado de trabalho no Brasil. Ciência e Cultura [online], 58(4). 42-43.

Gondim, S. M. G. (2002). Perfil profissional e mercado de trabalho: relação com formação acadêmica pela perspectiva de estudantes universitários. Estudos de Psicologia (Natal)

Haguette, T. M. F. (2001). Metodologias qualitativas na sociologia. Petrópolis, SP: Editora Vozes.

Ianni, O. (1994). Globalização: novo paradigma das ciências sociais. Estudos Avançados [online], 8(21). 147-163.

Leite, E. M. (1996). Reestruturação produtiva, trabalho e qualificação no Brasil. In Bruno, L. (Org.). Educação e trabalho no capitalismo contemporâneo: leituras selecionadas. (pp. 146-87). São Paulo, SP: Atlas.

Levin, E. (1997) A infância em cena - Constituição do sujeito e desenvolvimento psicomotor. Petrópolis, RJ: Vozes.

Libâneo, J. C. (2006). Diretrizes curriculares da pedagogia: imprecisões teóricas e concepção estreita da formação profissional de educadores.Educação \& Sociedade, 27(96), 843-876.

Libâneo, J.C. (2005). Pedagogia e pedagogo, para quê? São Paulo, SP: Cortez Editora . (2002). Pedagogia e Pedagogos, Para Quê? São Paulo, SP: Cortez Editora.

Louro, G. L. (1997) Gênero, sexualidade e educação: uma perpectiva pós-estruturalista. Petrópolis, RJ: Vozes; CNTE.

Mancebo, D. (2002). Globalização, cultura e subjetividade: discussão a partir dos meios de comunicação de massa. Psicologia: Teoria e Pesquisa [online], 18(3). 289-295.

Martín-Baró, I. (1998). Psicología de la liberación. Madrid: Editorial Trotta. 
. (1999). Sistema, grupo y poder: psicologia social desde centroamérica (II). San Salvador, El Salvador: UCA Editores.

MEC/INEP. Sinopse estatística da educação básica,2002. Disponível em: http://www.inep.gov.br/basica/censo/Escolar/Sipnopse/sinopse_2002.htm.

Minayo, S. C. M. (1994). Ciência, técnica e arte: o desafio da pesquisa social. In Minayo, S. C. M. (Org.). Pesquisa Social: teoria, método e criatividade. (pp. 09-15). Petrópolis, RJ: Vozes.

Narodowski, M. (1993) Infância e poder: A confrontação da pedagogia moderna. (Tese de Doutorado em Educação). Universidade Estadual de Campinas, Campinas, SP. Recuperado de http://www.bibliotecadigital.unicamp.br/document/?code=vtls000072112 em 19 de junho de 2015.

Nóvoa, A. (1999). Profissão Professor. Porto, Portugal: Editora Porto. . (1999). Vida de professores. Porto, Portugal: Editora Porto.

Penna Soares, S. H., \& Sestren, Gisele (2007). Projeto Profissional: O redimensionamento da carreira em tempos de privatização. Psicologia \& Sociedade, 19(spe), 66-74. DOI: 10.1590/S0102-71822007000400010.

Pereira, E. M. de A., Fiorentini, D., \& Geraldi, C. M. G. (Orgs.) (1999). Cartografias do Trabalho Docente. Educação \& Sociedade, 68(Ano XX). Campinas, SP: Cedes.

Perrenoud, P. (2001). Formando professores profissionais: Quais estratégias? Quais competências? Porto Alegre, RS: Artmed Editora.

Pimenta, S. G. (2000). Didática e formação de professores: percursos e perspectivas no Brasil e em Portugal.São Paulo, SP: Cortez.

. (1997). O Estágio na Formação de Professores - Unidade Teoria e Prática. São Paulo, SP: Cortez Editora.

Pimenta, S. G., \& Ghedin, E. (Orgs.) (2005). Professor Reflexivo no Brasil, Gênese e Crítica de um Conceito. São Paulo, SP: Cortez Editora.

Rêses, E. da S. (2008). De vocação para profissão: organização sindical docente e identidade social do professor. (Tese de Doutorado em Sociologia). Universidade de Brasília, Brasília. DOI: 10.1590/S0102-69922008000200012.

Resolução do Conselho Nacional de Educação para o Curso de Pedagodia (CNE/CP), n. ${ }^{\circ}$ $1 / 2006$ (2006). 
Salerno, M. S. (1994). Trabalho e organização na empresa industrial integrada e flexível. In Ferretti, C. J., Zibas, D. M. L., Madeira, F. R., \& Franco, M. L. P.B. (Orgs.). Novas tecnologias, trabalho e educação: um debate multidisciplinar. (pp. 54-76). Petrópolis, RJ: Vozes.

Scherer, A. L. F. (1997). Globalização. In Cattani, A. D. Trabalho e tecnologia Dicionário crítico. (pp. 114-119). Petrópolis, RJ: Vozes.

Romanowski, J. P. (2007). Formação e profissionalização docente. Curitiba, PR: IBEPEX.

Rousseau, J-J. (1995). Emilio ou da educação. (3 ${ }^{\mathrm{a}}$ ed.). Rio de Janeiro, RJ: Bertrand Brasil.

Sayão, D. T. (2005). Relações de gênero e trabalho docente na Educação Infantil: um estudo de professores em creche. (Tese de Doutorado em Educação). Universidade Federal de Santa Catarina, Florianópolis. Recuperado do Repositório Institucional da UFSC

https://repositorio.ufsc.br/bitstream/handle/123456789/106572/223081.pdf?sequence $=1$ em 19 de junho de 2015 .

Silva, C. S. B. da. (2003). Curso de Pedagogia no Brasil. História e Identidade. Campinas, SP: Editora Autores Associados.

Tardif, M., \& Lessard, C. (2005). O trabalho Docente. Elementos para uma Teoria da Docência como profissão de Interações Humanas. Petrópolis, RJ: Editora Vozes.

Tardif, M., \& Raymond, D. (2000). Saberes, tempo e aprendizagem do trabalho no magistério. Educação \& Sociedade, 21(73). Campinas, SP: CEDES.

Teixeira, F. J. S. (Org.) et al. (1996). Neoliberalismo e Reestruturação Produtiva. São Paulo, SP: Cortez Editora.

Teo, T. (2015). A Psicologia na "Jangada da Medusa": entrevistado por Toassa, G. In Psicologia \& Sociedade, 27(2), 460-469. Recuperado de http://www.ufrgs.br/seerpsicsoc/ojs2/index.php/seerpsicsoc/article/view/3887 em 13 de maio de 2015.

Vaillant, D. (2009). A profissão Docente. In Schwartzman, S., \& Cox, C. Políticas Educacionais e coesão social: uma agenda latino-americana. (Christophe, M. \$ Caldas, R., Trads.). Rio de Janeiro, RJ: Elsevier; São Paulo, SP: iFHC. 
Valore, L. A., \& Viaro, R.V. (2007). Profissão e Sociedade no Projeto de Vida de adolescentes em Orientação Profissional. Curitiba, PR: Universidade Federal do Paraná.

Vieira Pinto, A. (1960). Consciência e Realidade Nacional-A consciência ingênua. (Vol. 1). Rio de Janeiro, RJ: MEC/ISEB.

Villela, H. O. S. (1992). A primeira Escola Normal do Brasil. In Clarice Nunes. (Org.). O passado sempre presente. (pp. 17-42). São Paulo, SP: Cortez. 